\title{
Regioselective protection of myo-inositol orthoesters - recent developments
}

\author{
M. S. Shashidhar \\ Division of Organic Synthesis, National Chemical Laboratory, Pune 411 008, INDIA \\ E-mail:shashi@dalton.ncl.res.in
}

(received 08 May 02; accepted 23 Jun 02; published on the web 01 Jul 02)

\begin{abstract}
There has been a revival of interest in the chemistry of cyclitols in the recent past due to the discovery of phosphoinositol based signal transduction mechanisms in eukaryotic systems. Traditionally, synthesis of inositol derivatives involved the protection of its hydroxyl groups as the corresponding ketals. However, recently orthoesters of myo-inositol have emerged as convenient intermediates for the synthesis of inositol derivatives. The present account describes recent progress in the chemistry related to myo-inositol orthoesters.
\end{abstract}

Keywords: Inositol, signal transduction, cyclitol, protecting groups, second messenger

\section{Introduction}

Chemistry and biology of myo-inositol derivatives has been investigated extensively in the recent past due to the involvement of phosphoinositols in cellular signal transduction mechanisms ${ }^{1}$ and anchoring of certain proteins to cell membranes. ${ }^{2}$ Although a bewildering array of myo-inositol phosphates and their lipid derivatives have been identified and / or isolated from plant as well as animal sources, the biological roles played by many of them is not yet clearly understood. However, receptors and effectors involved in various stages of phosphoinositol based signal transduction pathways remain potential targets for pharmacological intervention in states of disease. ${ }^{\text {1c }}$ These developments in biology and medicine have necessitated the efficient synthesis of naturally occurring phosphoinositols and their synthetic analogs. Consequently, many methodologies and techniques have been developed, ${ }^{1 \mathrm{c}, 3}$ for the synthesis and isolation of phosphoinositols and their analogs.

The key intermediates for the synthesis of biologically important derivatives of inositols are the corresponding hydroxyl group protected derivatives (having free hydroxyl group(s) at desired positions). $O$-protected myo-inositol derivatives and their analogues have been prepared from (a) commercially available myo-inositol, ${ }^{3 \mathrm{a}, 3 \mathrm{~b}}$ (b) naturally occurring quebrachitol, ${ }^{4}$ (c) carbohydrates (glucose, ${ }^{3 c}$ D-xylose, ${ }^{5}$ D-galactose, ${ }^{6}$ D-mannitol, ${ }^{7}$ and L-iditol, ${ }^{8}$ ) (d) tartaric acid ${ }^{9}$ and (e) 
benzene and its derivatives. ${ }^{10}$ Among the different strategies developed for the synthesis of protected myo-inositol derivatives and their analogs, those starting from commercially available myo-inositol is many times preferred because of its low cost and convenience. Several efficient methods are now available for the desymmetrization or resolution of myo-inositol derivatives that can be used for the preparation of enantiomeric phosphoinositols and their analogs.

Traditionally, the first step in the preparation of $O$-protected myo-inositol derivatives was the ketalization of two or four hydroxyl groups of myo-inositol. These aspects have been extensively reviewed. $^{3 \mathrm{a}, 3 \mathrm{~b}, 11}$. However, in the last decade, protection of the C-1, C-3 and C-5 hydroxyl groups of myo-inositol as the corresponding orthoester has been frequently used. ${ }^{12}$ This is mainly because, orthoesters of myo-inositol can be easily obtained in gram quantities as a single product. $^{13}$. In contrast, ketalization of myo-inositol results in the formation of mixture of isomers, which require tedious chromatographic separation and/or the yield of individual isomers is seldom more than 30\%. Phosphoinositols and other compounds with interesting properties that have been synthesized starting from myo-inositol orthoesters are shown in Scheme 1.

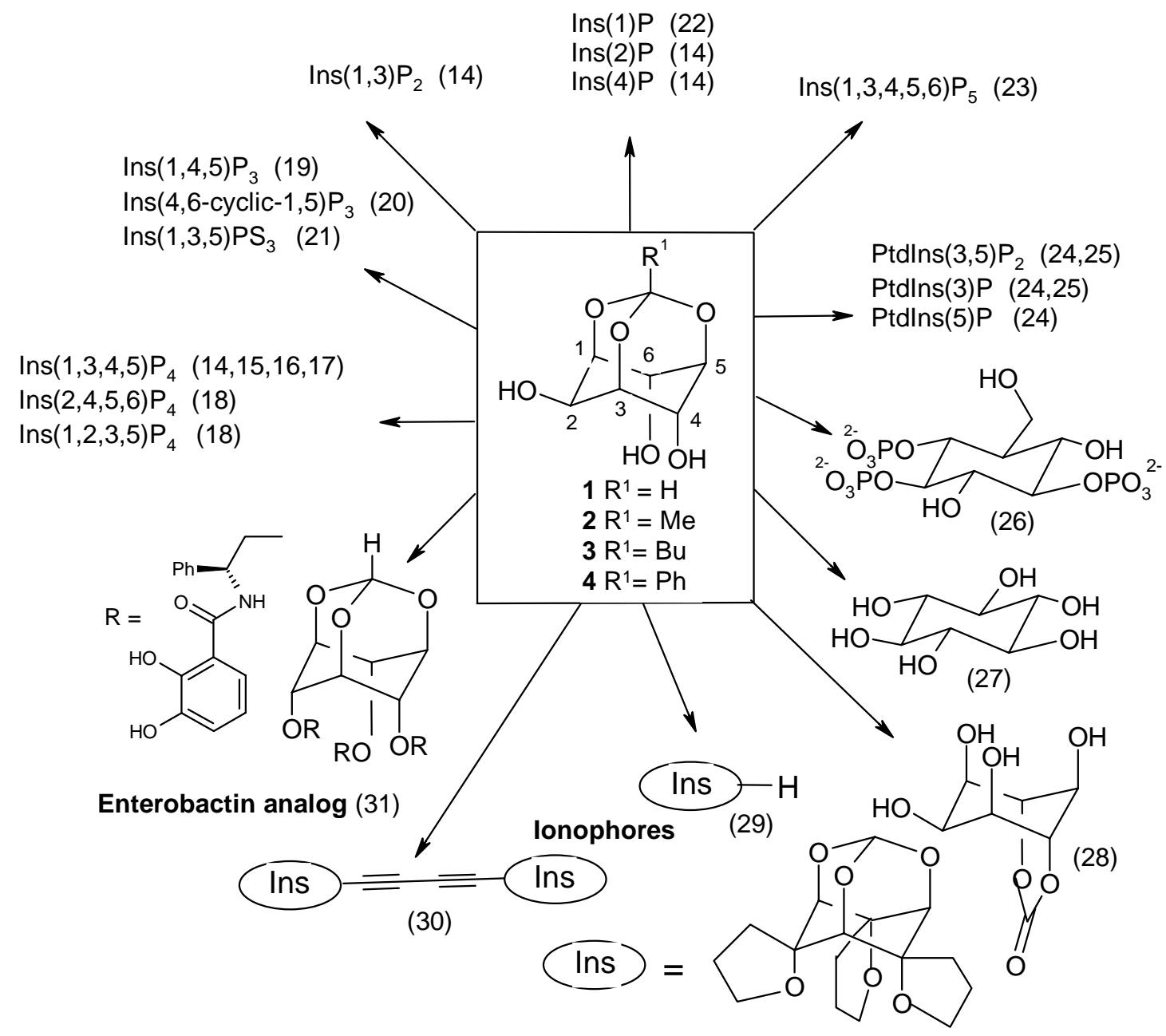

Scheme 1. Numbers in paranthesis indicate relevant references. 
Billington ${ }^{14}$ first reported the selective C-4-O-alkylation of the orthoformate $\mathbf{1}$ and its application for the preparation of a few myo-inositol phosphates. We have developed good methods for the selective functionalization of (a) only the C-2 or the C-4 hydroxyl group, ${ }^{32}$ (b) C-2 and C-4 (or C-6) hydroxyl groups simultaneously ${ }^{33}$ and (c) C-4 and C-6 hydroxyl groups simultaneously ${ }^{34}$ in 1 and 2. In the present account, results of our efforts towards the synthesis of $O$-protected inositol derivatives starting from orthoesters of myo-inositol is presented. In addition to being useful intermediates for the synthesis of phosphoinositols, orthoesters of myo-inositol exhibit interesting and unusual chemistry due to their rigid adamantane - like structure. These unusual chemical characteristics are also referred to, in relevant sections of this account.

\section{Preparation of myo-inositol orthoesters}

Although four orthoesters of myo-inositol (1-4, Scheme 1) are reported in the literature, most of the reports on the preparation of $O$-protected myo-inositol derivatives have utilized the orthoformate 1. Orthoesters of myo-inositol are prepared by the reaction of myo-inositol (5, Scheme 2) with ethyl or methyl orthoester of the desired carboxylic acid. They can be isolated (in $90 \%$ yield or more) by column chromatography or as the corresponding triacetate or the tribenzoate, without the aid of chromatography. The orthoesters 1-4 can be obtained by the methanolysis or aminolysis of the corresponding triacetate or the tribenzoate. Using these procedures, the required orthoester may be obtained on tens of grams to hundred-gram scale in a short time. ${ }^{13}$

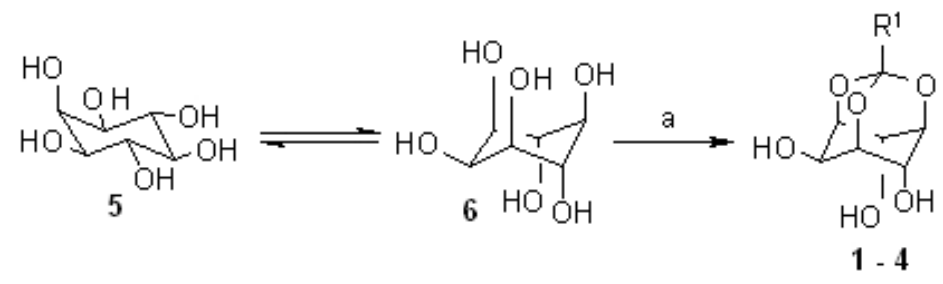

Scheme 2. (a) $(\mathrm{EtO})_{3} \mathrm{CR}^{1}$, DMF, $p$-TsA, $100{ }^{\circ} \mathrm{C}$

\section{Selective protection of myo-inositol orthoester hydroxyl groups Synthesis of $O$-protected myo-inositol derivatives}

\subsection{Protection of one of the hydroxyl groups of myo-inositol orthoesters}

Formation of 1,3,5-orthoesters of myo-inositol involves inversion of the inositol ring (6, Scheme 2). Consequently, these orthoesters have five oxygen atoms in axial position and an oxygen atom in the equatorial position with respect to the myo-inositol ring. Myo-inositol orthoesters are in fact highly functionalized adamantanes. Three of the carbon atoms in adamantane are replaced by three oxygen atoms ( $\mathrm{C}-1, \mathrm{C}-3$ and $\mathrm{C}-5$ oxygen atoms of the inositol ring) and three of the methylene groups of adamantane are hydroxylated (C-2, C-4 and C-6 of the inositol ring). This results in an analog of adamantane molecule, which has two pairs of 1,3-trans hydroxyl groups and one pair of 1,3-cis hydroxyl groups. The rigidity of the adamantane frame-work and the 
presence of six oxygen atoms in the molecule imparts unusual chemical and physical properties on myo-inositol orthoesters and its derivatives. All these orthoesters have the meso configuration and hence two of the hydroxyl groups (C-4 and C-6) are chemically equivalent. The C-4 and C-6 hydroxyl groups form a strong intramolecular hydrogen bond, ${ }^{15,35}$ (Scheme 3) as a result of which, one of these hydroxyl groups is more acidic than the C-2 hydroxyl group.

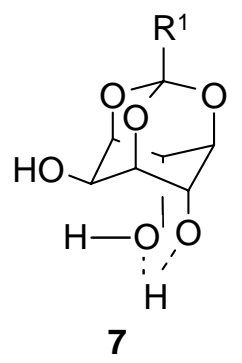

7

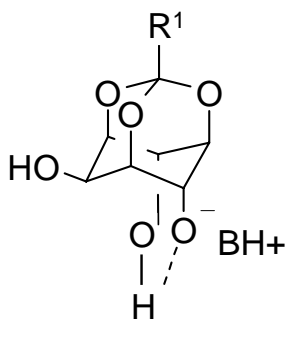

8

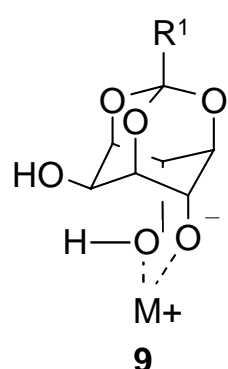

9

\section{Scheme 3}

Hence bases that can de-protonate the more acidic hydroxyl group (C-4 or C-6) result in the formation of the corresponding anion (8) which is also stabilized by intramolecular hydrogen bonding with the other axial hydroxyl group. When metal hydrides are used as bases, the resulting alkoxide at the C-4 or the C-6 hydroxyl group is stabilized by chelation (9) with the cishydroxyl group. As a result of these intramolecular interactions, selective mono functionalization of one of the 1,3-cis hydroxyl groups or the C-2 hydroxyl group can be achieved. ${ }^{14}$

Acylation of myo-inositol orthoesters (Scheme 4) with one equivalent of an acylating agent in the presence of a strong base such as triethylamine or sodium hydride (one equivalent) results in the formation of the corresponding C-4 (or C-6) ester. The use of excess of sodium hydride for mono acylation leads to the formation of the C-2 ester. This method for the acylation of the C-2 hydroxyl group gives the corresponding C-2-ester exclusively in excellent yields. ${ }^{32}$

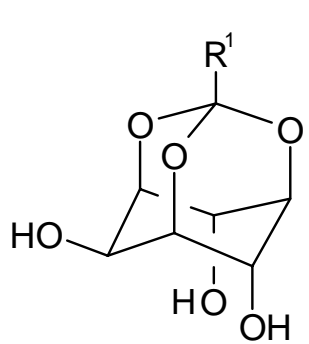

1. $\mathrm{R}^{1}=\mathrm{H}$

2. $\mathrm{R}^{1}=\mathrm{Me}$

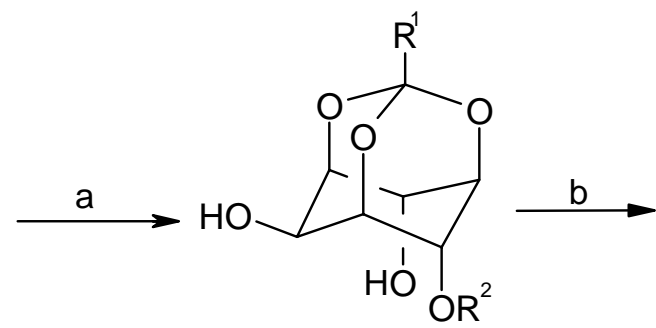

$10 \mathrm{R}^{1}=\mathrm{H} ; \mathrm{R}^{2}=\mathrm{AC}$

$11 \mathrm{R}^{1}=\mathrm{H} ; \mathrm{R}^{2}=\mathrm{Bz}$

$12 \mathrm{R}^{1}=\mathrm{H} ; \mathrm{R}^{2}=$ Pivaloyl

$13 \mathrm{R}^{1}=\mathrm{H} ; \mathrm{R}^{2}=$ Lauroyl

$14 R^{1}=M e ; R^{2}=B z$

$15 R^{1}=M e ; R^{2}=A c$

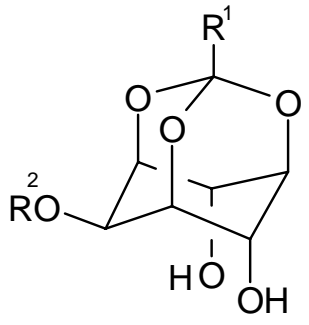

$16 \mathrm{R}^{1}=\mathrm{H} ; \mathrm{R}^{2}=\mathrm{Ac}$

$17 \mathrm{R}^{1}=\mathrm{H} ; \mathrm{R}^{2}=\mathrm{Bz}$

$18 \mathrm{R}^{1}=\mathrm{H} ; \mathrm{R}^{2}=$ Pivaloyl

$19 \mathrm{R}^{1}=\mathrm{H} ; \mathrm{R}^{2}=$ Lauroyl

$20 \mathrm{R}^{1}=\mathrm{Me} ; \mathrm{R}^{2}=\mathrm{Bz}$

$21 R^{1}=M e ; R^{2}=A C$

Scheme 4. (a) DMF, NaH (1 eq), $\mathrm{R}^{2} \mathrm{X}$, rt. ( $\mathrm{R}^{2} \mathrm{X}=\mathrm{acyl}$ chloride or anhydride).

(b) DMF, Nah, rt, 5 min. 
The different regioselectivities observed for the acylation of the orthoesters in the presence of one equivalent and excess of sodium hydride is due to an intramolecular acyl migration from C4-O-position to the C-2-O-position (Scheme 5). That this migration is intramolecular was suggested by carrying out the acyl migration in a mixture (equimolar) of the acetate $\mathbf{1 0}$ and the benzoate 14, which did not result in the formation of any cross products (17 or 21). It appears this migration takes place since the chelate $\mathbf{2 4}$ of the $\mathrm{C}-2$ ester is expected to be more stable than the chelates 22, 23 of the C-4 ester. It is interesting to note that this 1,3-trans acyl migration is quite facile in spite of the fact that formation of a tetrahedral intermediate is not possible due to rigidity of these molecules. It is likely that this migration proceeds in an $\mathrm{S}_{\mathrm{N}} 2$ like mechanism wherein bond formation $(\mathrm{C} 2-\mathrm{O} \ldots \mathrm{C}=\mathrm{O})$ and bond breakage $(\mathrm{C} 4-\mathrm{O}-\mathrm{C}=\mathrm{O})$ are simultaneous.
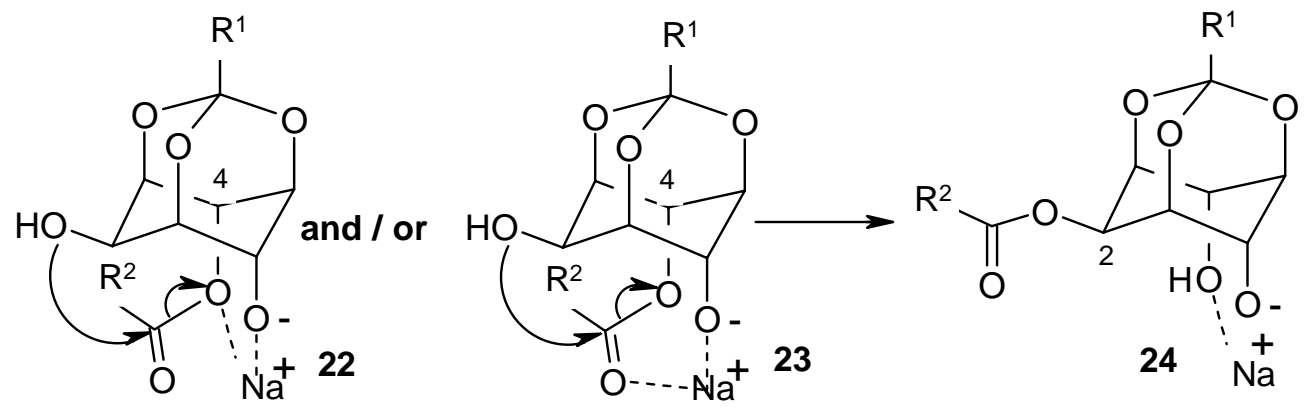

\section{Scheme 5}

It is important to note that regioselectivity observed during acylation of orthoesters of myoinositol in the presence of sodium hydride is the same irrespective of the acylating agent used. In contrast, regioselectivity for the acylation of these orthoesters in the presence of organic bases varies with the acylating agent. ${ }^{36}$ For instance, benzoylation of the triol $\mathbf{1}$ with benzoyl chloride, in the presence of pyridine $\left(\mathrm{pK}_{\mathrm{a}}=5.58\right)$ and triethylamine $\left(\mathrm{pK}_{\mathrm{a}}=11.01\right)$ yield the C-2-benzoate 17 and the C-4-benzoate 11 respectively. Triethylamine being a stronger base can perhaps deprotonate one of the axial hydroxyl groups, whose acidity is higher than that of normal alcohols (and the C-2-hydroxyl group) due to a very strong intramolecular hydrogen bond ${ }^{35}$ (Scheme 6). The resulting anion 25 is also stabilized by intramolecular hydrogen bonding and hence benzoyl chloride preferentially reacts at the C-4(6)-O position. Pyridine being a weaker base, cannot deprotonate the C-4(6) hydroxyl group; and hence the reactivity among the

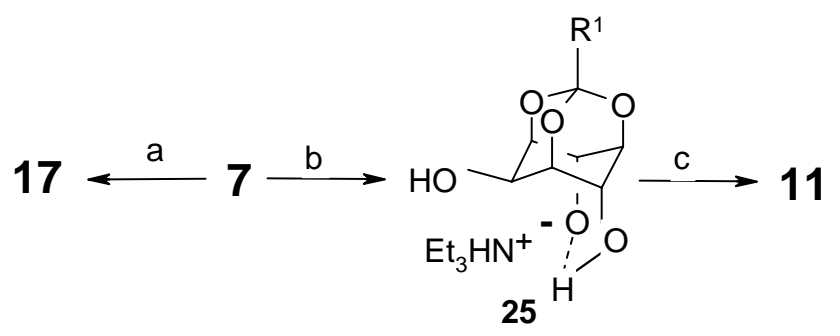

Scheme 6. (a) Pyridine, BzCl; (b) $\mathrm{Net}_{3}$; (c) BzCl. 
three hydroxyl groups of $\mathbf{1}$ is determined by the relative nucleophilicity and steric factors. Since the axial C-4(6) hydroxyl groups are more acidic than the C-2-hydroxyl group, they are expected to be less nucleophilic than the C-2-hydroxyl group, and as a result, benzoylation takes place at the C-2-O position, in pyridine. Steric hindrance for $O$-substitution at the axial C-4(6)-Oposition may also contribute to the observed selectivity for the reaction in pyridine, since the benzoylating species in pyridine is thought to be the bulky benzoyl pyridinium ion. ${ }^{36}$

Regioselectivity observed for the sulfonylation of the orthoesters $\mathbf{1}$ and $\mathbf{2}$ (Scheme 7) is similar to that observed during their acylation. Use of stronger bases (sodium hydride,

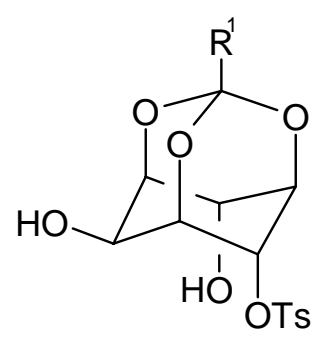

26. $R^{1}=H$

27. $\mathrm{R}^{1}=\mathrm{Me}$

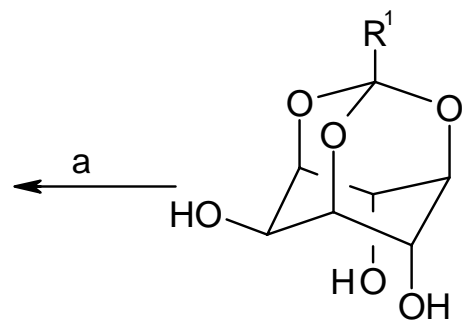

1. $\mathrm{R}^{1}=\mathrm{H}$

2. $\mathrm{R}^{1}=\mathrm{Me}$

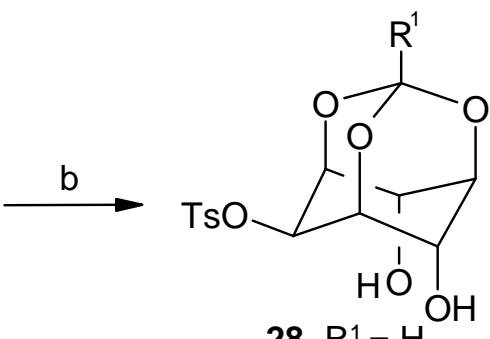

28. $\mathrm{R}^{1}=\mathrm{H}$

Scheme 7. (a) DMF, $\mathrm{NaH}$ (or $\mathrm{Net}_{3}$ ), TsCl, rt. (b) Pyridine, TsCl, rt.

triethylamine) results in the formation of the C-4 sulfonate (26 or 27) while the use of pyridine results in the formation of the C-2 sulfonate (28 or $\mathbf{2 9}$ ). However, the C-4 sulfonates (26 or $\mathbf{2 7}$ ) cannot be converted to the corresponding C-2 sulfonates (28 or $\mathbf{2 9}$ ) by treatment with excess sodium hydride, as in the case of carboxylic acid esters (Scheme 4). We have demonstrated ${ }^{34}$ that myo-inositol orthoester hydroxyl groups can be selectively protected as alkyl or aryl sulfonates and these sulfonates can be deprotected by cleavage with magnesium in methanol or sodium methoxide in methanol.

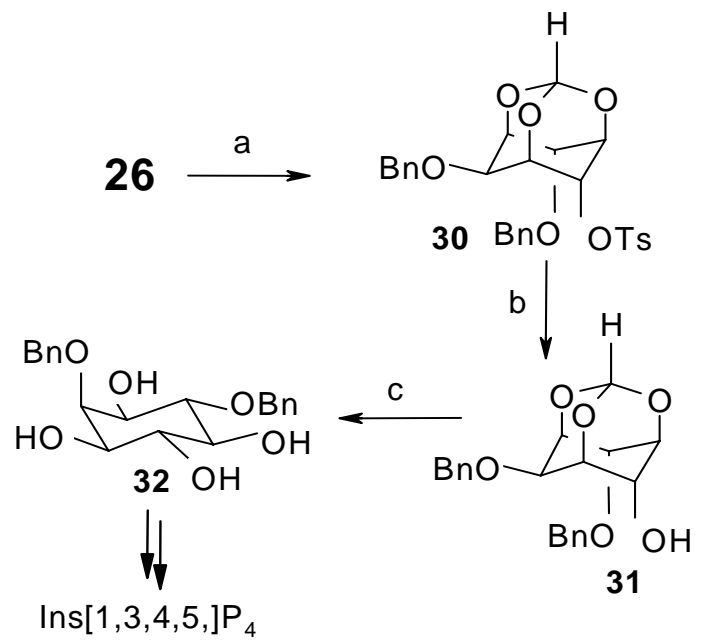

Scheme 8. (a) NaH, BnBr; (b) Mg / MeOH; (c) Aq. TFA. 
Table 1. A comparison of the overall yield of racemic (32) as well as D- and L-2,4-di-O-benzylmyo-inositol reported in the literature

\begin{tabular}{|c|c|c|c|}
\hline Entry & Key intermediate & Yield(\%) $)^{\mathrm{a}}$ & Ref \\
\hline 1 & Myo-inositol 1,3,5-orthoformate & $33.3^{\mathrm{b}}$ & 38 \\
\hline 2 & 1,3,4,5-tetra-O-benzoyl-myo-inositol & 17 & 39 \\
\hline 3 & Myo-inositol 1,3,5-orthoformate & 35 & 40 \\
\hline 4 & Myo-inositol 1,3,5-orthoformate & 75 & 37 \\
\hline 5 & Myo-inositol 1,3,5-orthoformate & $27(27)^{\mathrm{c}}$ & 17 \\
\hline 6 & Myo-inositol 1,3,5-orthoformate & $12(13)$ & 15 \\
\hline 7 & Myo-inositol 1,3,5-orthoformate & $15(14)$ & 15 \\
\hline 8 & 1,2;4,5-di-O-cyclohexylidene myo-inositol & $3^{\mathrm{d}}$ & 41 \\
\hline 9 & 1,3,5-tri-O-benzoyl-myo-inositol & 8 & 42 \\
\hline 10 & (-)-2,3;4,5-di-O-cyclohexylidene-myo-inositol & 7 & 43 \\
\hline 11 & Myo-inositol 1,3,5-orthoformate & 37 (39) & 37 \\
\hline
\end{tabular}

${ }^{\mathrm{a}}$ From myo-inositol. ${ }^{\mathrm{b}}$ Entries 1-4 for racemic dibenzyl ether 32. ${ }^{\mathrm{c}}$ For L- and (D-) isomers respectively. ${ }^{\mathrm{d}} \mathrm{L}$ - enantiomer obtained by enzyme mediated enantio-selective acylation.

Using this method of protection - deprotection (Scheme 8) we could obtain the 2,4-dibenzyl ether in better yield ${ }^{37}$ than the previously reported methods. The racemic dibenzyl ether $\mathbf{3 1}$ can be resolved as camphanate esters to prepare enantiomeric dibenzyl ethers 32 which are precursors for the preparation of $\mathrm{D}$ - and L-Ins $(1,3,4,5) \mathrm{P}_{4}$. The yields obtained by using sulfonate protection and other methods of protection reported in the literature are compared in Table 1.

\subsection{Simultaneous protection of C-2 and C-4 hydroxyl groups of myo-inositol orthoesters}

The C-2 and C-4 hydroxyl groups of myo-inositol orthoesters can be protected simultaneously by benzoylation in the presence of pyridine. ${ }^{33}$ As mentioned in the previous section, the first acylation takes place at the C-2-hydroxyl group resulting in the formation of the symmetric diol 17, which undergoes further acylation to yield the corresponding unsymmetrical racemic dibenzoate 33. We have $\operatorname{shown}^{13,44}$ that the racemic dibenzoate $\mathbf{3 3}$ can be used for the preparation of several useful $O$-protected myo-inositol derivatives (Scheme 9). The orthoformate moiety in the dibenzoate $\mathbf{3 3}$ can be cleaved to obtain the tetrol $\mathbf{3 4}$ which is an intermediate for the preparation of racemic $\operatorname{Ins}(1,3,4,5) \mathrm{P}_{4}$. The yield of the tetrol 34 obtained from 33 is about $60 \%$ (from myo-inositol) which is much better than the previous report ${ }^{45}(18 \%)$ that used diisopropylidene-myo-inositol as an intermediate. The dibenzoate $\mathbf{3} 3$ can be converted to the dibenzyl ether $\mathbf{3 8}$ by benzylation with benzyl bromide in the presence of silver(I) oxide. This alkylation reaction can be effected with any alkyl bromide or iodide. ${ }^{46}$ The conversion of 33 to the corresponding diether proceeds through the intermediacy of the corresponding monoalkyl ether (such as 35). ${ }^{46,47}$ This was exploited for the synthesis of racemic ononitol (36). ${ }^{44}$ Detailed investigation of this alkylation reaction revealed the catalytic role of silver halides (generated during alkylation) in bringing about the cleavage of the C-4 benzoate. ${ }^{12}$ 


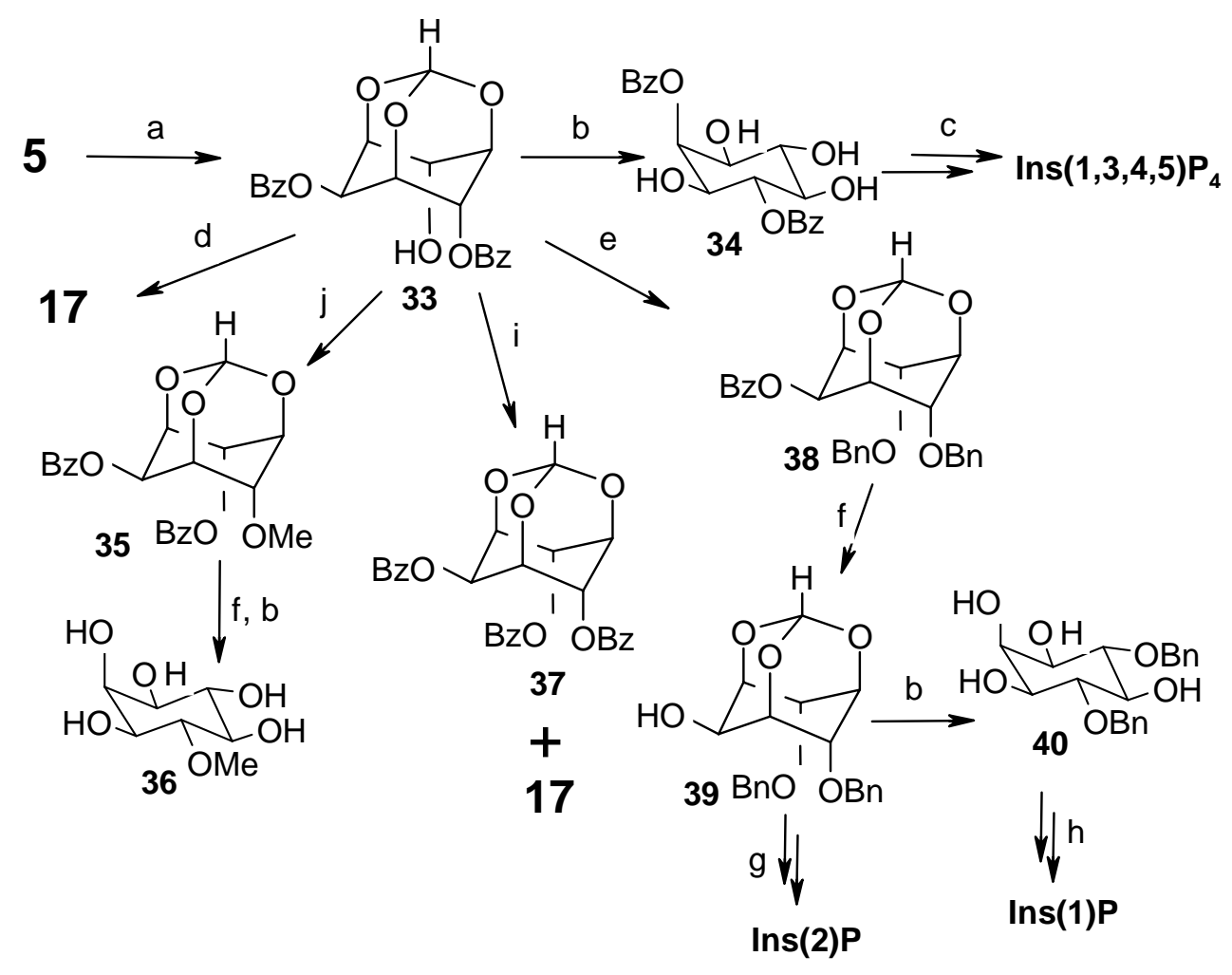

Scheme 9. (a) i. HC(OEt) $)_{3}$ H+; ii. Pyridine, BzCl; (b) Aq. TFA; (c) As in ref. 45; (d) MeOH, pyridine; (e) DMF, $\mathrm{Ag}_{2} \mathrm{O}, \mathrm{BnBr}$, (f) lsobutylamine, $\mathrm{MeOH}$; (g) As in ref. 14; (h) As in ref. 22; (i) $\mathrm{Na}_{2} \mathrm{CO}_{3}, 140{ }^{\circ} \mathrm{C}$; (j) DMF, $\mathrm{Ag}_{2} \mathrm{O}, \mathrm{Mel}, 1 \mathrm{~h}$.

The dibenzyl ether $\mathbf{4 0}$ which is the key intermediate for the preparation of Ins(1)P could be obtained in an overall yield of $67 \%$ (from myo-inositol) without the use of chromatography via benzylation of the dibenzoate 33. ${ }^{13}$ Yield (from myo-inositol) by literature methods ${ }^{14,22,48}$ for the preparation of $\mathbf{4 0}$ does not exceed $\mathbf{4 5 \%}$ and involve chromatographic methods of separation. This approach (i.e., diacylation of $\mathbf{1}$ and 2) has also been used by others for the efficient synthesis of myo-inositol-1,3,4,5-tetraphosphate ${ }^{16}$ and myo-inositol-1,4,5-triphosphate. ${ }^{49}$

The C-4 benzoate in $\mathbf{3 3}$ can be selectively solvolyzed to obtain the diol 17. The preferential solvolysis of the C-4 benzoate over the $\mathrm{C}-2$ benzoate is due to the intramolecular general base catalysis of the C-6 hydroxyl group. ${ }^{33}$ The dibenzoate $\mathbf{3 3}$ undergoes facile transesterification reaction to give the corresponding tribenzoate $\mathbf{3 7}$ and the diol $\mathbf{1 7}$ in solution ${ }^{47}$ as well as solid states. $^{50}$ The facile reaction in the solid state is due to the packing of the molecules in crystals of the dibenzoate 33 , which orients the two reacting molecules in a manner that is most suitable for 
the intermolecular acyl transfer reaction. ${ }^{50}$ This reaction constitutes the first example of nucleophilic addition to a carbonyl group in the solid state.

Disulfonylation of myo-inositol orthoester $\mathbf{1}$ in the presence of pyridine or triethylamine also results in the formation of the corresponding racemic 2,4-disulfonate $\mathbf{4 1}^{37}$ However the intermediate monosulfonates involved in the triethylamine and pyridine catalyzed reactions are respectively the 4-sulfonate $\mathbf{2 6}$ and the 2-sulfonate $\mathbf{2 8}$ (Scheme 10).

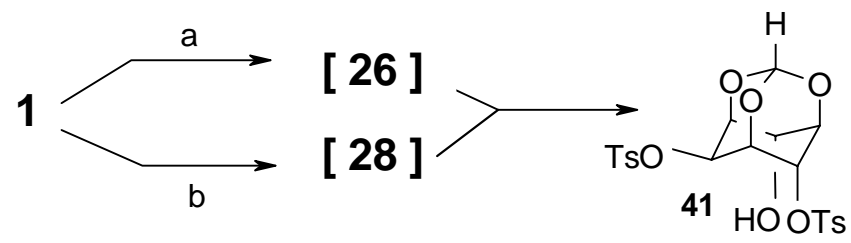

Scheme 10. (a) TsCl, Et ${ }_{3} \mathrm{~N}$; (b) TsCl, pyridine.

\subsection{Simultaneous protection of C-4 and C-6 hydroxyl groups of myo-inositol orthoesters}

As seen in section 3.1, monoalkylation of the myo-inositol orthoesters exclusively results in the formation of the C-4(6)-monoethers $\left(43 \mathrm{R}^{2}=\right.$ alkyl, Scheme 11). In these monoethers (43), the two hydroxyl groups are more or less of equal acidity and hence their reaction with sodium hydride leads to the formation of both the possible alkoxides $\mathbf{4 4}$ and $\mathbf{4 5}$. As a result, dialkylation of the triol 1 results in the formation of both the possible diethers $\mathbf{4 6}$ and $\mathbf{4 7}$. Although, the 4,6diether $\mathbf{4 6}$ is formed in larger amounts as compared to the 2,4-diether $\mathbf{4 7}$ (due to the stabilization of the axial alkoxide $\mathbf{4 4}$ due to chelation) the isolated yield of 4,6-di-O-substituted derivative 46 was about $40 \%$ or less. ${ }^{14,20,26,28}$ We have reported $^{13}$ a method for the protection of C-4 and C-6 hydroxyl groups in 1 via the dibenzoate 33 (Scheme 9) in better yields (60-65\%).

Diacylation of the triols $\mathbf{1}$ or $\mathbf{2}$ to obtain the symmetrical diesters is also not a facile process, since the regiospecificity of this reaction is dependent on the nature of the acylating agent, reaction conditions, nature of the base used and the possibility of inter- or intramolecular acyl migration. (see previous sections). We theorized that since sulfonyl groups are less prone to migration among hydroxyl groups (as compared to acyl groups), and also posses two oxygen atoms which could aid in the stabilization of the C-4 alkoxide, disulfonylation of the triols $\mathbf{1}$ and 2 would result in the formation of the corresponding symmetrical 4,6-disulfonates $\mathbf{5 0}$. Indeed, disulfonylation of the triols $\mathbf{1}$ and $\mathbf{2}$ in the presence of excess of sodium hydride resulted in the formation of the corresponding symmetrical disulfonates $\mathbf{5 0}$ in good yields (Scheme 11). ${ }^{34}$

Detailed investigation of the ditosylation of the orthoformate $\mathbf{1}$ under a variety of conditions suggested the possibility of involvement of myo-inositol derivative-sodium chelates (48, 49, Scheme 11) which could be responsible for the preferential formation of symmetrical 4,6disulfonates 50. This method provides a short route for the preparation of 2-O-substituted myoinositol derivatives as well as myo-inositol-1,3,4,5,6-pentaphosphate. Using this approach, we could obtain 2-O-benzyl-myo-inositol (53, Scheme 12) in an overall yield of 58\% in five steps from myo-inositol, which is much better than the reported ${ }^{51}$ yield of $10 \%$ in seven steps. 


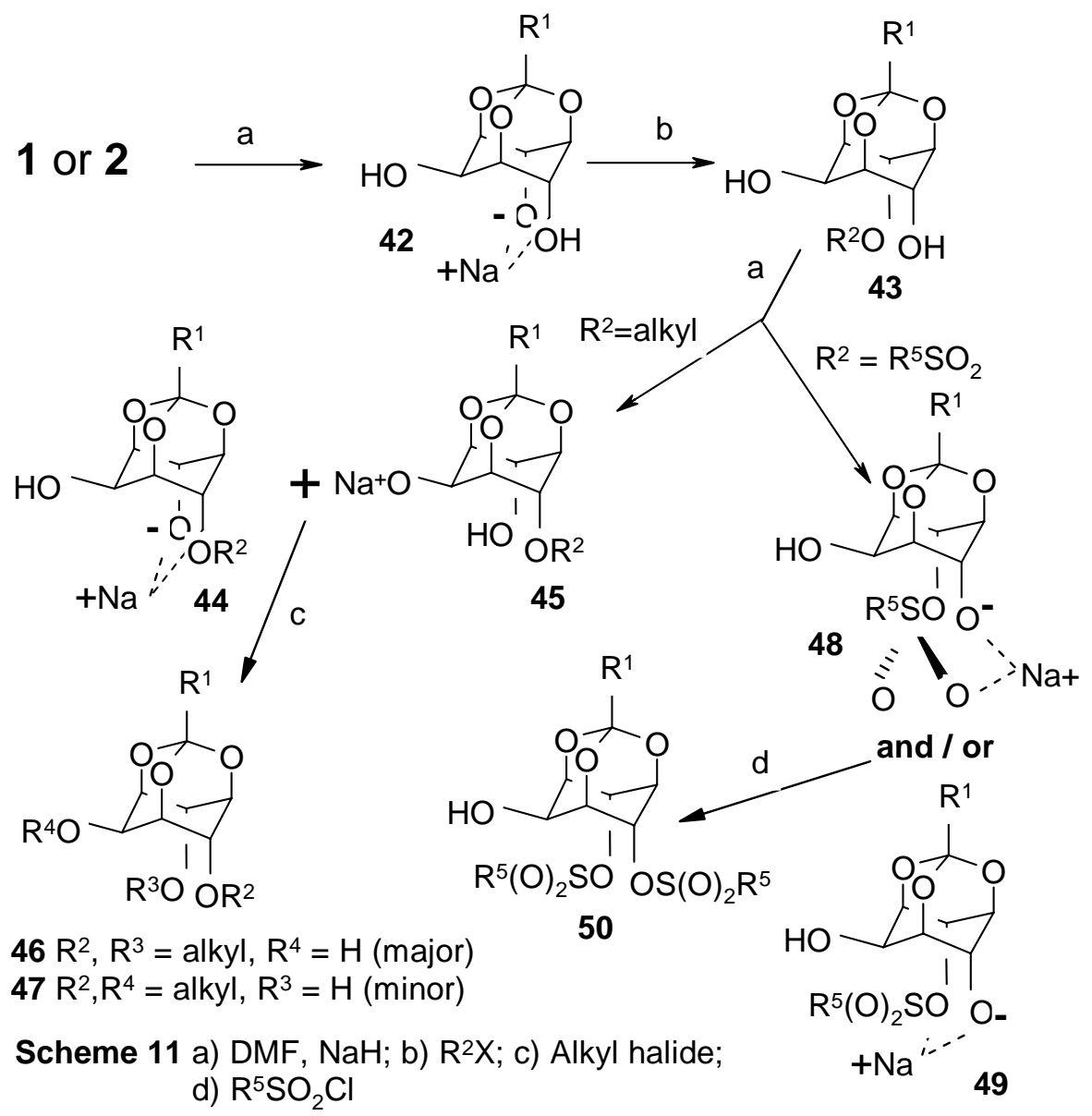

Scheme 11. (a) DMF, NaH; (b) $\mathrm{R}^{2} \mathrm{X}$; (c) Alkyl halide; (d) $\mathrm{R}^{5} \mathrm{SO}_{2} \mathrm{Cl}$.

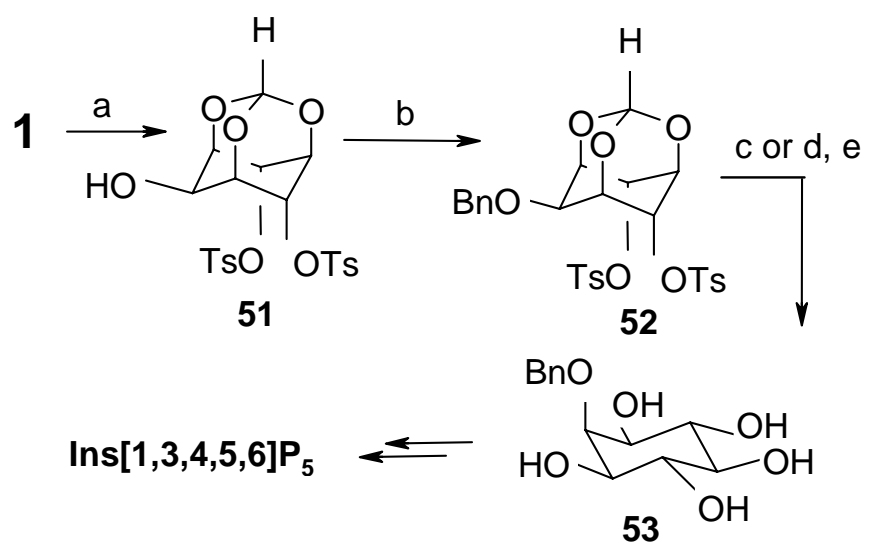

Scheme 12. (a) DMF, NaH, TsCl; (b) DMF, NaH, BnBr; (c) NaOMe, $\mathrm{MeOH}$; (d) Mg / MeOH; (e) Aq. TFA.

It is pertinent to mention that the use of sulfonate groups for the protection of alcohols is not usually encountered during organic synthesis because of the difficulties in their deprotection. 
The sulfonate groups function as good leaving groups and result in nucleophilic substitution at the carbon carrying the sulfonate group or elimination to form olefins. Although sulfonate derivatives of cyclitols have been synthesized earlier, ${ }^{52-58}$ they have not been used for the protection of hydroxyl groups, since the parent hydroxyl group could not be regenerated easily. However, myo-inositol orthoesters being trioxa analogs of adamantane, nucleophilic substitution at the carbon carrying the sulfonate group in them is difficult. It is known in the literature ${ }^{59}$ that solvolysis of adamantan-2-ol tosylate or 2-bromoadamantane proceeds predominantly with retention of configuration. Furthermore, replacement of a methylene group in adamantane by an oxygen atom is known to appreciate the extent of retention of configuration during solvolysis. ${ }^{60}$

Because of the structural resemblance of orthoesters of myo-inositol with adamantane, we expected $O$-sulfonylated myo-inositol orthoester derivatives to undergo solvolysis with retention of configuration. Also, the presence of three endocyclic oxygen atoms in myo-inositol orthoesters (trioxaadamantane) should favor retention of configuration during solvolysis of their sulfonate derivatives. The examples presented in this account show that sulfonate groups can be successfully used as efficient protecting groups for myo-inositol hydroxyl groups.

In conclusion, we have developed methods for the selective protection of any of the three hydroxyl groups of myo-inositol orthoesters as the corresponding carboxylic acid esters, sulfonate esters and ethers. These newer methods of protection and / or deprotection can be used to prepare important $O$-protected myo-inositol derivatives in better yields as compared to those reported in the literature.

\section{Acknowledgements}

The Department of Science and Technology, New Delhi supported this work. (Grant No. SP/S1/G-21/98)

\section{References}

1. Hinchliffe, K.; Irvine, R. Nature 1997, 390, 123. (b) Schmittberger, T.; Waldmann, H. Synlett. 1998, 574. (c) Phosphoinositides: Chemistry, Biochemistry and Biomedical applications Bruzik, K. S. Ed.; ACS Symposium Series 718. American Chemical Society: Washington D.C. USA, 1999.

2. Ferguson, M. A. J.; Williams, A. F. Annu. Rev. Biochem. 1988, 57, 285.

3. (a) Billington, D. C. The Inositol Phosphates. Chemical Synthesis and Biological Significance. VCH: New York, 1993. (b) Potter, B. V. L.; Lampe, D. Angew. Chem., Int. Ed. 1995, 34, 1933. (c) Prestwich, G. D. Acc. Chem.Res. 1996, 29, 503.

4. Chida, N.; Sakata, N.; Murai, K.; Tobe, T.; Nagase, T.; Ogawa, S. Bull. Chem. Soc. Jpn. 1998, 71, 259. 
5. (a) Jenkin, D. J.; Potter, B. V. L. J. Chem. Soc. Perkin Trans. 1 1998, 41. (b) Clive, D. L. J.; He, X.; Poslema, M. H. D.; Mashimbye, M. J. J. Org. Chem. 1999, 64, 4397.

6. Dubreuil, D.; Cleophax, J.; Almeida, M. V.; Verre-Sebrie, C.; Liaigre, J.; Vass, G. and Gero, S. D. Tetrahedron, 1997, 53, 16747.

7. Chiara, J. L.; Martin-Lomas, M. Tetrahedron Lett. 1994, 35, 2969.

8. Guidot, J. P.; Le Gall, T.; Miskowski, C. Tetrahedron Lett. 1994, 34, 6671.

9. Sawada, T.; Shirai, R.; Iwasaki, S. Tetrahedron Lett. 1996, 37, 885.

10. Hudlicky, T. Chem Rev. 1996, 96, 3.

11. Stepanov, A. E.; Shvets, V. I. Chem. Phys. Lipids 1979, 25, 247.

12. Praveen, T.; Das, T.; Sureshan, K. M.; Shashidhar, M. S.; Samanta, U.; Pal, D.; Chakrabarti, P. J. Chem. Soc., Perkin Trans 2 2002, 358 and references cited therein.

13. Praveen, T.; Shashidhar, M. S. Carbohydr. Res. 2001, 330, 409 and references cited therein.

14. Billington, D. C.; Baker, R.; Kulagowski, J. J.; Mawer, I. M.; Vacca, J. P.; deSolms, S. J.; Huff, J. R. J. Chem. Soc., Perkin Trans.1 1989, 1423.

15. Baudin, G.; Glanzer, B. I.; Swaminathan, K. S.; Vasella, S. Helv. Chim. Acta 1988, 71, 1367.

16. Riley, A. M.; Mahon, M. F.; Potter, B. V. L. Angew. Chem., Int. Ed. 1997, 36, 1472.

17. Laumen, K.; Ghisalba, O. Biosci. Biotech. Biochem. 1999, 63, 1374.

18. Chung, S-K.; Chang, Y-T. Bioorg. Med. Chem. Lett. 1997, 7, 2715.

19. Garret, S. W.; Liu, C.; Riley, A. M.; Potter, B. V. L. J. Chem. Soc., Perkin Trans.1 1998, 1367.

20. Ballereau, S.; Poirier, S. N.; Guillemette, G.; Spiess, B.; Schlewer; G. J. Chem. Soc., Perkin Trans.1 1998, 1859.

21. Lampe, D.; Liu, C.; Potter, B. V. L. J. Med. Chem. 1994, 37, 907.

22. Laumen, K.; Ghisalba, O. Biosci. Biotech. Biochem. 1994, 58, 2046.

23. Chung, S.; Chang, Y. Bioorg. Med. Chem. Lett. 1996, 6, 2039.

24. Falck, J. R.; Murali Krishna, U.; Kattipally, K. R.; Capdevila, J. H.; Ulug, E. T. Tetrahedron Lett. 2000, 41, 4271.

25. Painter, G. F.; Grove, S. J. A.; Gilbert, I. H.; Holmes, A. B.; Raithby, P. R.; Hill, M. L.; Hawkins, P. T.; Stephens, L. R. J. Chem. Soc., Perkin Trans.1 1999, 923.

26. Riley, A. M.; Murphy, C. T.; Lindley, C. J.; Westwick, J.; Potter, B. V. L. Bioorg. Med. Chem. Lett. 1996, 6, 2197.

27. Lee, H. W.; Kishi, Y. J. Org. Chem. 1985, 50, 4402.

28. Angyal, S. J. Carbohydr. Res. 2000, 325, 313.

29. Tae, J.; Rogers, R. D.; Paquette, L. A. Org. Lett. 2000, 2, 139.

30. Paquette, L. A.; Tae, J.; Gallucci, J. C. Org. Lett. 2000, 2, 143.

31. Tse, B.; Kishi, Y. J. Am. Chem. Soc. 1993, 115, 7892.

32. Sureshan, K. M.; Shashidhar, M. S. Tetrahedron Lett. 2000, 41, 4185.

33. Banerjee, T.; Shashidhar, M. S. Tetrahedron Lett. 1994, 35, 8053.

34. Sureshan, K. M.; Shashidhar, M. S. Tetrahedron Lett. 2001, 42, 3037. 
35. Uhlmann, P.; Vasella, A. Helv. Chim. Acta 1992, 75, 1979.

36. Flores-Mosquera, M.; Martín-Lomas, M.; Chiara, J. L. Tetrahedron Lett. 1998, 39, 5085.

37. Sureshan, K. M.; Praveen, T.; Shashidhar, M. S. (Submitted for publication).

38. de Solms, S. J.; Vacca, J. P.; Huff, J. R. Tetrahedron Lett. 1987, 28, 4503.

39. Watanabe, Y.; Shinohara, T.; Fujimoto, T.; Ozaki, S. Chem. Pharm. Bull. 1990, 38, 562.

40. Billington, D. C.; Baker, R. J. Chem. Soc., Chem. Commun. 1987, 1011.

41. Ozaki, S.; Kondo, Y.; Nakahira, H.; Yamaoka, S.; Watanabe, Y. Tetrahedron Lett. 1987, 28, 4691.

42. Watanabe, Y.; Oka, A.; Shimizu, Y.; Ozaki, S. Tetrahedron Lett. 1990, 31, 2613.

43. Gou, D-M.; Chen, C-S. Tetrahedron Lett. 1992, 33, 721.

44. Das, T.; Shashidhar, M. S. Carbohydr. Res. 1998, 308, 165.

45. Meek, J. L.; Davidson, F.; Hobbs Jr. F. W. J. Am. Chem. Soc. 1988, 110, 2317.

46. Das, T.; Shashidhar, M. S. Carbohydr. Res. 1997, 297, 243.

47. Das, T.; Praveen, T.; Shashidhar, M. S. Carbohydr. Res. 1998, 313, 55.

48. Andersch, P.; Schneider, M. P. Tetrahedron: Asymmetry 1993, 4, 2135.

49. Garrett, S. W.; Liu, C.; Riley, A. M.; Potter, B. V. L. J. Chem. Soc., Perkin Trans. 1 1998, 1367.

50. Praveen, T.; Samanta, U.; Das, T.; Shashidhar, M. S.; Chakrabarti, P. J. Am. Chem. Soc. 1998, 120, 358.

51. Lu, P-J.; Gou, D-M.; Shieh, W-R.; Chen, C-S. Biochemistry 1994, 33, 11586.

52. Cadenas, R. A.; Aguilar, G. J.; Gelpi, M. E. Carbohydr. Res. 1986, 148, 153.

53. Mosettig, J.; Gelpi, M. E.; Cadenas, R A. Carbohydr. Res. 1981, 98, 51.

54. Baer, H. H.; Arai, I.; Radatus, B.; Rodwell, J; Chinh, N. Can. J. Chem. 1987, 65, 1443.

55. Guedat, P.; Spiess, B.; Schlewer, G. Tetrahedron Lett. 1994, 35, 7375.

56. Suami, T.; Ogawa, S.; Oki, S.; Kunitomo, H. Bull. Chem. Soc. Jpn. 1974, 47, 1737.

57. Suami, T.; Ogawa, S.; Oki, S.; Sato, H. Bull. Chem. Soc. Jpn. 1974, 47, 1731.

58. Suami, T.; Ogawa, S.; Funaki, Y. Bull. Chem. Soc. Jpn. 1975, 48, 1545.

59. Bone, J. A.; Whiting, M. C. Chem. Comm. 1970, 115.

60. Subramaniam, R.; Fort, R. C. Jr. J. Org. Chem. 1984, 49, 2891. 